\title{
Editorial for Special Issue: Recent Developments in Multi-Media and Underwater Photogrammetry
}

\author{
Hans-Gerd Maas ${ }^{1} \cdot$ Thomas Luhmann ${ }^{2}$ \\ Accepted: 10 February 2022 / Published online: 23 February 2022 \\ (c) The Author(s) 2022
}

Three-dimensional reconstruction of objects or processes using 3D imaging methods (photogrammetry, computer vision, laser scanning) is still associated with particular challenges in applications involving multiple optical media (e.g. under water). These challenges concern under water imaging and the optical properties of the medium water as well as geometric modelling. In the photogrammetric literature, the term 'multi-media photogrammetry' has been established for this. Although the essential mathematical principles of beam modelling in the multi-media case and the associated calibration of cameras have been fundamentally developed for decades, new challenges that go beyond arise in many applications. For example, new sensor technologies increasingly allow the use of autonomous systems, which in turn lead to new research questions and sensor fusion concepts. Autonomous systems require advanced methods of positioning under water and, associated with this, new methods of data transmission and communication. Consumer-grade cameras are now available for underwater use and thus open new possibilities for low-cost solutions. Advances in automatic image analysis and image matching are opening up new application areas in multi-media photogrammetry, for example for localising objects underwater. Finally, machine learning methods also show interesting potential for this field. On the other hand, aspects such as turbidity or turbulence in the medium can lead to considerable limitations in visibility, altered imaging properties and a significant loss of accuracy.

In the PFG theme issue at hand, five topical contributions from experts in their respective areas of expertise are brought together, and recent research results are presented. The focus is on novel sensor concepts for 3D underwater imaging (Sardemann et al., Kahmen and Luhmann, advanced geometric modelling and accuracy analyses (Rofallski and Luhmann, Bräuer-Burchardt et al.) as well as on questions of object and scene reconstruction and optical digital twins through methods of optical 3D measurement technologies (Nakath et al.). As such, the issue is complementing the 2021 PFG special issue on bathymetry from images, lidar, and sonar edited by Prof. Mandlburger (2021/2, https://link. springer.com/journal/41064/volumes-and-issues/89-2), thus substantiating the leading position of our journal in cutting edge research in photogrammetry and related fields.

Funding Open Access funding enabled and organized by Projekt DEAL.

Open Access This article is licensed under a Creative Commons Attribution 4.0 International License, which permits use, sharing, adaptation, distribution and reproduction in any medium or format, as long as you give appropriate credit to the original author(s) and the source, provide a link to the Creative Commons licence, and indicate if changes were made. The images or other third party material in this article are included in the article's Creative Commons licence, unless indicated otherwise in a credit line to the material. If material is not included in the article's Creative Commons licence and your intended use is not permitted by statutory regulation or exceeds the permitted use, you will need to obtain permission directly from the copyright holder. To view a copy of this licence, visit http://creativecommons.org/licenses/by/4.0/.
Hans-Gerd Maas

hans-gerd.maas@tu-dresden.de

Thomas Luhmann

luhmann@jade-hs.de

1 Technische Universität Dresden, Dresden, Germany

2 Jade Hochschule, Oldenburg, Germany 